\title{
A rede social Facebook e suas aplicações no ensino de química
}

\author{
Daniele Raupp*, Marcelo Leandro Eichler ${ }^{* *}$
}

Resumo: As ferramentas da Web 2.0 têm possibilitado diversas formas de publicação, compartilhamento e organização de informações, fazendo que a sociedade esteja vivendo em rede. A interatividade e colaboração passaram a fazer parte do dia a dia dos usuários. As potencialidades do uso de ferramentas como redes sociais, blogs, wikis e podcasts têm sido foco de interesse de várias pesquisas no ensino de ciências. Neste trabalho buscamos identificar na rede social Facebook páginas e comunidades ativas que de alguma forma divulgam temas relacionados à química e suas ligações com outra ferramenta da Web 2.0: os blogs.

Palavras-chave: redes sociais, blogs; TIC's, web 2.0, ensino de química.

Abstract: [The Facebook social network and its applications in chemical education]. The Web 2.0 tools have enabled various forms of publishing, sharing and organizing information, configuring a true information society. Interactivity and collaboration have become part of everyday users. The potential use of tools like social networks, blogs, wikis and podcasts has been the focus of several studies in science education. In this work we seek to identify the social network Facebook pages and active communities that somehow publicize issues related to chemistry and its connections with other Web 2.0 tools, like blogs.

Keywords: social networks, blogs, ICT, web 2.0, chemistry teaching.

\section{$\underline{\text { Introdução }}$}

Nas últimas décadas temos vivenciado um rápido aumento no uso das tecnologias de informação e comunicação (TIC) na sociedade. Fato que pode ser atribuído, segundo Selwyn (2003) à emergência dos computadores pessoais, internet e televisão digital. Segundo Castells (1999) a convergência desses meios faz com que estejamos vivendo em uma "sociedade em rede". O autor esclarece que:

É claro que a tecnologia não determina a sociedade. Nem a sociedade escreve o curso da transformação tecnológica, uma vez que muitos fatores, inclusive criatividade e iniciativa empreendedora, intervêm no processo de descoberta científica, inovação tecnológica e aplicações sociais, de forma que o resultado final depende de um complexo padrão interativo (Castells, 2006).

Pode-se dizer a emergência da sociedade do conhecimento implica que cada cidadão possua uma cultura digital e as aptidões de base para dispor de uma igualdade de oportunidades mais efetiva em um mundo em que se multiplicam as mediações digitais, inclusive no âmbito das relações sociais. Nesse sentido, um estudo encomendado pelo MEC (Waiselfisz, 2007) revelou que diversas pesquisas têm mostrado os resultados positivos para a comunidade escolar da inclusão das tecnologias de informação e comunicação (TIC's) nas estratégias de ensino e no ambiente escolar. Segundo os professores, o desempenho dos estudantes em diversos temas e nas habilidades consideradas básicas (cálculo, leitura e escrita, por exemplo) melhora com o

\footnotetext{
* Licenciada em Química e Mestre em Ensino de Ciências pela ULBRA, doutoranda em Educação em Ciências na UFRGS, professora do Centro Universitário Metodista, do IPA. Autora correspondente: dtraupp@gmail.com

** Licenciado em Química e Doutor em Psicologia do Desenvolvimento pela UFRGS, professor da UFSC.exlerbr@yahoo.com.br
} 
uso das TIC's. Além disso, essas tecnologias possuem fortes efeitos motivacionais e resultados positivos nos comportamentos dos alunos, incentivando os trabalhos em grupo e a colaboração entre os estudantes.

As mídias sociais são um tema da moda no momento. As mídias sociais têm influenciado as práticas em muitos campos orientados pela comunicação, tais como marketing, atendimento ao cliente e jornalismo. Na educação, o hype em torno mídias sociais criou muita especulação sobre como elas podem ser usado em um ambiente de ensino (Hrastinski e Dennen, 2012). As perspectivas podem variar desde estratégias formais de ensino que se valem das tecnologias e dos dispositivos eletrônicos para distribuir informação e fazer avaliações até estratégias menos formais, que visam a integrar efetivamente uma tecnologia, cuja utilização naturalista tem sido tão fortemente informal e orientada para o utilizador, em um ambiente escolar conhecido por suas experiências mais formais e estruturadas (Hrastinski e Aghaee, 2011).

Nessa nova sociedade a questão da interatividade tem um papel de destaque. A Web 2.0 - termo usado para definir a chamada segunda geração da internet - é fortemente marcada pela interatividade, pelos conteúdos gerados por usuários e pela personalização de serviços. Com isso, a internet deixou de ser uma plataforma em que uma informação pronta era divulgada, com um portal de jornais e revistas, para ser um meio de divulgação livre de conteúdos. Alguns exemplos de sites típicos dessa geração são os blogs - uma abreviação de weblog que significa registro eletrônico na internet (e as variações fotologs e videologs), as redes sociais e os sites de compartilhamento de arquivos.

Primo (2007) considera que a Web 2.0 é caracterizada por potencializar as diversas formas de publicação, de compartilhamento e de organização de informações, além disso, possui a capacidade de ampliar os espaços para a interação entre os participantes do processo. E ainda comenta que: "A Web 2.0 tem repercussões sociais importantes, que potencializam processos de trabalho coletivo, de troca afetiva, de produção e circulação de informações, de construção social de conhecimento apoiada pela informática". Almeida (2008) defende que o uso da Web 2.0, além de potencializar a conexão e o acesso instantâneo a informações, permite a participação e a co-autoria por meio de uma série de interfaces. Esse trabalho coletivo permite usar todo o potencial de colaboração da internet de uma forma simples.

Simões e Gouveia (2009) afirmam que as tecnologias de informação, nas últimas duas décadas, foram as responsáveis por uma profunda reorganização do modo como as pessoas vivem, comunicam e aprendem. Principalmente porque a utilização desse tipo de tecnologias tem permitido a construção de novos espaços de construção de conhecimentos e tem permito alargar o tempo em que as aprendizagens podem ocorrer (Coutinho; Bottentuit, 2007). As potencialidades do uso de ferramentas de comunicação por meio da web 2.0 no ensino de ciências têm sido foco de interesse de várias pesquisas. Alguns pesquisadores concentram seu foco nos blogs (Millan e Real, 2011; Moresco e Behar, 2006; Gutierrez, 2005; Barro, Ferreira e Queiros, 2008a e 2008b) e outros pesquisam o impacto das redes sociais (Barcelos, Passerino e Behar, 2010; Bassani e Heidrich, 2008; Leite e Leão, 2010).

Analisando especificamente essas duas ferramentas: blogs e redes sociais, cabe considerar uma relação existente entre ambos que está se tornando cada vez mais comum quanto à difusão de conhecimentos. Essa relação permite que as redes sociais exerçam o papel de divulgar e difundir informações, em pequenos posts que estão mais bem apresentadas nos blogs. Assim, buscamos com este artigo analisar as relações entre a rede social Facebook e os blogs relacionados à química, utilizando como suporte as 
metodologias de classificação de blogs de ensino de ciências propostas Brownstein e Klein (2006) e Barros (2009).

O contexto das ferramentas da web 2.0 no ensino

A Web 2.0 está provocando, segundo Dede (2008), uma mudança da epistemologia clássica da educação para uma nova epistemologia, baseada em pedagogias de aprendizagem ativas. Selwyn (2007) comenta que com o surgimento dessas tecnologias colocamos alunos no centro das atividades e supostamente facilitamos novas formas de criação e colaboração.

Hoje há muita informação circulando na rede. Muita informação sobre ciências e tecnologia. Existem blogs especializados em diferentes campos das ciências. Os avançamentos da biologia, da física e da química tem sido divulgados em diversos espaços, tanto em espaços mais formais e tradicionais, como a Revista Ciência Hoje, como através das ferramentas inovadoras, como a versão brasileira da rede de blogs ScienceBlogs. Porém, por diversos motivos, essas ferramentas não são muito utilizadas no cotidiano escolar. Dentre as inúmeras ferramentas e as possibilidades da Web 2.0, as mais difundidas e utilizadas em contextos educativos, segundo Bottentuit Junior e Coutinho (2007), estão os blogs, os wikis e os podcasts.

Um dos formatos de publicação mais populares na web surgiu nos anos 1990 (Silva, 2007), o blog (abreviação da palavra weblog) "pode ser descrito como um website extremamente flexibilizado com mensagens organizadas em ordem cronológica reversa e com uma interface de edição simplificada, através da qual seu autor pode inserir novos posts" (Silva, 2003) ou simplesmente uma página Web de fácil edição onde os posts aparecem organizados em uma ordem cronologicamente pré-determinada. Um post, nada mais é na linguagem dos blogueiros, o ato de postar, é uma atualização ou a alimentação de alguma informação no blog. Em resumo, podemos considerar que os blogs são baseados em ferramentas que facilitam a criação, edição e manutenção de uma página na web.

Uma das grandes vantagens dos blogs é que, as ferramentas existentes permitem que os usuários publiquem seu conteúdo sem a necessidade de um conhecimento técnico sobre construção de páginas na Internet. Atualmente, até mesmo quem já possui site pode, está aproveitando as vantagens das ferramentas de blog para atualizar seu conteúdo de maneira rápida e intuitiva:

Os weblogs são baseados em mecanismos que facilitam a colocação de um website no ar. Geralmente possuem layouts prontos e dispensam a necessidade de que o blogueiro saiba a linguagem HTML, principal problema para a colocação de conteúdo na Web. A maioria dos weblogs é baseada também nos princípios de microconteúdo (textos curtos, com as informações relevantes, colocados de modo padrão - em blocos - no site, denominados posts), e atualização frequente (geralmente, diária. Em alguns casos, os weblogs são atualizados várias vezes ao dia). (Recuero, 2003)

Dreves (2004) comenta que é comum que os blogs, em seus posts, contenham links de outros blogs, que, em geral, postam assuntos correlacionais, e dessa forma, estabelece-se uma espécie de corrente. Há também, segundo o mesmo autor, o chamado "ciclo de visitação". Esse ciclo se estabelece quando um blogueiro visita outros blogs, deixando comentários e indicando o endereço de sua página.

Mas o que motiva as pessoas a escreverem e dedicarem tempo na manutenção de seus blogs? Segundo Bar-Illan (2005) os principais motivos são: (1) necessidades de expressão pessoal; (2) necessidade de reconhecimento; (3) necessidade de contato social; (4) necessidade de introspecção; (5) partilha de conhecimentos e de informação acadêmica; (6) expressão artística. 
De um modo geral, qualquer registro frequente de informações pode ser considerado um blog. Atualmente existem blogs que são uma espécie de diário pessoal digital, que trazem as mais diversas experiências e vivencias de seus autores. Os blogs podem ser classificados segundo Silva (2003) de acordo com sua estrutura e seu gênero. Quanto à sua estrutura, os blogs podem ser classificados em:

a) Blogs individuais: O conteúdo de um blog individual é postado por uma única pessoa embora e os visitantes possam publicar comentários em espaços determinados. Em geral são blogs que apresentam opiniões, relatos, informações e textos escritos do ponto de vista de alguém em específico. $\mathrm{O}$ espaço para comentários, disponível em qualquer que seja o tipo de blog, mas nem sempre adotado por todos, é um espaço aberto para interatividade.

b) Blogs coletivos: $\mathrm{O}$ administrador do blog tem a opção permitir que múltiplos autores participem da manutenção do mesmo site, motivados por interesses semelhantes.

Quanto ao gênero, os blogs podem ser classificados em:

a) Blogs Temáticos: Produzido individualmente ou em grupos, este tipo de blog é concebido com base em um tema específico ou numa área de interesse em comum. São exemplos de blogs temáticos, os que têm propósitos educacionais e pedagógicos, jornalísticos, metablogs (blogueiros que se propõe a ensinar outros blogueiros), entre outros.

b) Blogs Livres: As publicações desse tipo de blog não têm como foco uma única temática, e em geral estão associados às características próprias de uma página pessoal, por se tratarem de formas livres de anotações, que podem incluir criação literária, comentários sobre o que se passa na cabeça do autor, críticas, fofocas, atualização de notícias, diários, entre outros.

Em relação às redes sociais, Siemens (2008), comenta que o desenvolvimento tecnológico e os softwares sociais estão alterando significativamente a maneira pela qual os aprendizes acessam a informação e o conhecimento, dialogando entre si e com o professor.

Os softwares sociais são programas que funcionam como mediadores sociais e que favorecem a criação de redes de relacionamentos através de espaços onde o usuário pode juntar pessoas do seu círculo de relacionamentos, conhecer outras que compartilhem os mesmos interesses e discutir temas variados, construindo diferentes elos entre os "eus" privado e público (Machado e Tijiboy, 2005)

As redes sociais ou redes de relacionamentos virtuais visam a impulsionar as relações humanas através da tecnologia. Castells (2002) comenta que relação de sociabilidade nas redes socias pode ser caracterizada como laços "fracos" e "fortes"; e esses vínculos transcendem a distância, a baixo custo. Além disso, em geral, apresentam uma característica assíncrona, com uma rápida propagação da informação e favorecem afiliações múltiplas.

Nas redes sociais é muito comum a formação de comunidades virtuais que segundo Castells (1999) são definidas "como uma rede eletrônica de comunicação interativa autodefinida, organizada em torno de um interesse ou finalidade compartilhados, embora algumas vezes a própria comunicação se transforme no objetivo". Capra (2008) complementa afirmando que redes sociais são redes de comunicação que envolve linguagem simbólica, restrições culturais, relação de poder etc. Essas ferramentas são usadas bastante utilizadas para fazer amigos ou reencontrar , compartilhar fotos, vídeos e comentários. 
No Brasil as redes sociais mais utilizadas são Messenger, Orkut, Ning, Foursquare, Facebook, Skype, Twitter, Linkedin e Formspring. Uma dessas redes era descrita por Selwyn (2007) nos seguintes termos:

Facebook é um ambiente relativamente convencional de redes sociais online, modelado ostensivamente sobre "livros do ano" das escolas dos EUA, onde breves perfis escritos de alunos de entrada são apresentados ao lado de uma fotografia. Na versão eletrônica, os usuários apresentam-se aos outros dentro de um quadro semelhante, embora muito mais extensa.

Uma análise das redes sociais e blogs de ensino de química no Brasil

Em março de 2012 começamos uma atividade de autoria de um blog e de difusão de informações sobre didática das ciências na rede social Facebook. Nossa atividade junto ao blog e à rede social nos levou a conhecer importantes iniciativas de difusão relacionadas à química. No Facebook, o usuário pode criar um perfil, página oficial, grupo ou comunidade. Para a análise deste artigo, selecionamos algumas páginas e comunidades relacionadas à química.

A página TabelaPeriódica.Org entrou no Facebook em fevereiro de 2011, mas começou a ter atualizações mais regulares a partir de dezembro, quando começou a distribuir vídeos sobre os elementos químicos e as substâncias elementares produzidos pelo professor Martyn Poliakoff, da Universidade de Nottingham. A página do Facebook é utilizada para divulgar os posts que são incluídos em um blog homônimo, ambos os serviços são organizados e mantidos pelo professor Luís Roberto Brudna Holzle, da Unipampa, em Bagé. O professor Brudna, também, faz as traduções dos vídeos sobre tabela periódica produzidos por Poliakoff e edita as legendas das versões em língua portuguesa.

A página Diário de um Químico Digital existe desde janeiro de 2012 e é mantida pelo professor Márcio Martins, do Centro Universitário Franciscano (UNIFRA), em Santa Maria (RS). O autor indica, expressamente, que a página tem o propósito de: "divulgar o conteúdo do blog e postar atualidades sobre Química, Ciências, TICs e o que mais vier à minha cabeça".

A página Ensino de Química existe desde janeiro de 2011 e é mantida pela professora Alcione Torres, da Universidade Estadual do Sudoeste da Bahia (UESB). A página do Facebook serve para divulgar o blog homônimo e assuntos relacionados à utilização das tecnologias da informação e comunicação no ensino de química.

A comunidade $A I Q$ - criada em 2011 para divulgar o Ano Internacional da Química, se mantém ativa e também tem um blog divulga assuntos relacionados à importância da química nas soluções de questões globais muitas curiosidades sobre a presença da Química no cotidiano, vídeos, notícias, podcasts etc.

A comunidade All Kimiya foi criada, em dezembro de 2011, pelo estudante Fernando Floria, bolsista do PIBID (Programa Institucional de Bolsas de Iniciação à Docência) do curso de licenciatura em química da Universidade Federal de Alfenas (MG). O blog de mesmo nome divulga informações diversas relacionadas ao cotidiano de um estudante de química.

Várias outras comunidades e páginas que estão apenas no Facebook se dedicam a difundir e replicar publicações com vídeos, desenhos, memes ou pequenos textos que tratam de assuntos sobre química, principalmente com alguma abordagem graciosa ou divertida. Pode-se citar como exemplos a seguintes comunidades: i) Química Ensinada, que começou suas publicações em junho de 2011, mas não se identifica o autor, indica que tem por missão divulgar o ensino de química, por que: "A Química contribui para o desenvolvimento da humanidade!"; ii) Química Anormal, cujo autor não é apresentado, é classificada ironicamente como "produtos químicos", começou suas postagens em 
outubro de 2011 e traz a pergunta como informação sobre a página: "Em algum momento química já foi normal?" iii) Química da Depressão, que começou em outubro de 2011 , não se identifica o autor, mas relata que a página existe "porque estudar química não é pra qualquer um..."; iv) Quimicando, que começou em fevereiro de 2012 e não se identifica o autor; v) Desequilíbrio Químico e Ligação Irônica, que começaram em fevereiro e março de 2012, respectivamente, e são mantidas pela estudante Bárbara Stephane, que estuda graduação em bacharelado em Química na Universidade Estadual Santa Cruz, em Ilhéus, na Bahia.

Por fim, talvez a melhor experiência atual de utilização do Facebook para a divulgação da química. O Canal Fala Química é descrita como uma revista e é autopromovido como o maior canal de divulgação da ciência e pesquisa química no Facebook. São considerados pioneiros na difusão da Química pelo Twitter e pelo Facebook, tendo iniciado suas publicações em fevereiro de 2011 o Canal Fala Química é o mais antigo entre as páginas e comunidades analisados neste artigo. O portal é uma continuidade das atividades de divulgação científica empreendidas pelos professores Edson Minatti, da UFSC, que durante vários anos editou a revista digital sobre química QMCWeb. O professor Ricardo José Nunes, da mesma instituição, colabora com a seleção de informações e com as publicações. Nesse canal há dezenas de publicações semanais, que divulgam vídeos, imagens, textos e resenhas de artigos acadêmicos, entre outros formatos, com uma grande ênfase às informações tecnológicas e científicas contemporâneas da química. Nesse sentido, o canal presta um serviço de seleção que se constitui um veículo de informações atualizadas para seus seguidores.

Uma ação de destaque nesse canal, que ajuda na criação da identidade da comunidade virtual consiste na exposição de fotos de estudantes de química no laboratório. O canal sugere que ele tem a "MAIOR galeria de QUÍMICOS da Internet, com mais de 1000 participantes: VOCÊ de JALECO, na EXPOSIÇÃO de QUÍMICOSno-LAB (grifos presentes na própria publicação)". Nesse sentido, pode-se considerar que o Canal Fala Química formou uma comunidade virtual, no sentido descrito por Castells (1999), e que ela poderia ser o foco de análises futuras acerca das características e interações das comunidades virtuais de ciência e tecnologia, particularmente, de química.

Portanto, podemos perceber relação entre as páginas ou comunidades com os respectivos blogs. Esses blogs, como comentado anteriormente, estão sendo utilizados como ferramenta de compartilhamento de conhecimentos e informação no contexto acadêmico. Segundo Carvalho e colaboradores (2006), um blog educacional pode ser considerado como um espaço eletrônico individual ou coletivo próprio para se partilhar informações, ideias, opiniões, materiais e referências. Esse espaço pode ser destinado tanto para leitura quanto para produção de textos que podem ser comentados e até mesmo questionados pelos leitores. Esse tipo de blog pode ser adotado em diferentes disciplinas, por alunos e professores, e qualquer um dos níveis de ensino.

Além da classificação geral, comentada anteriormente, Brownstein e Klein (2006), propõe uma classificação para os blogs de ensino de ciências quanto à modalidade e autoria dos blogs. Assim, quanto à modalidade, os blogs podem ser classificados em:

a) Aprendizado: estão relacionados os blogs com temas Argumento, Comentários, Pesquisa e Escrita

b) Interação: estão relacionados os temas Comunicação, Discussão, Pares e Comunidade.

Selecionamos dentre as páginas do Facebook alguns blogs que estão descritos e classificados na Tabela 1: 
Tabela 1 - Classificação de blogs de química

\section{Classificação}

\begin{tabular}{llllll}
\hline Nome do Blog & Endereço & Estrutura & Gênero & Modalidade & Autoria \\
TabelaPeriódica.Org & http://www.tabelaperiodica.org/ & Coletivo & Temático & Aprendizado & Professor \\
$\begin{array}{l}\text { Diário de um } \\
\text { Químico Digital }\end{array}$ & http://diariodeumquimicodigital.com/ & Individual & Temático & Aprendizado & Professor \\
Ensino de Química & http://ensquimica.blogspot.com.br/ & Individual & Temático & Aprendizado Professor \\
All Kimiya & http://allkimiya.blogspot.com.br/ & Individual & Temático & Aprendizado Aluno \\
AIQ & http://blog.quimica2011.org.br/ & Coletivo & Temático & Aprendizado Professor \\
Química Ensinada & http://quimicaensinada.blogspot.com.br/ & Individual & Temático & Aprendizado Professor \\
Canal Fala Química & http://falaquimica.com/ & Individual & Temático & Aprendizado Professor \\
\hline
\end{tabular}

Já a classificação quanto aos objetivos buscados com a aplicação dos blogs, segundo Barro (2009), que apresenta uma identificação de objetivos de utilização de blogs em várias áreas de ensino: servir como repositórios de informações; promover debates e discussões; promover a construção do conhecimento; promover a aprendizagem reflexiva; promover a aprendizagem colaborativa; promover habilidades de leitura e escrita; criar espaços de interação e/ou cooperação aluno-aluno e/ou alunoprofessor; promover o letramento digital; promover a aquisição de competências de comunicação; promover a exploração didática e pedagógica dos blogs na formação de professores; promover a prática reflexiva na formação de professores. A maior parte dos blogs, das páginas e comunidades do Facebook analisadas tem por objetivo divulgar informações relacionadas à ciência química, algumas vezes dando ênfase aos aspectos relacionados ao ensino dessa disciplina.

\section{Conclusão:}

Uma vez que a maior parte das páginas de blogs ou do Facebook parece estar destinada a compartilhar informações e conhecimentos sobre a ciência química, identificamos a possibilidade de promover outro viés em relação aos conhecimentos em química e, em ciências, de modo geral, que pudesse estar mais próximo do ambiente de formação e de atuação do professor de química (e de ciência, por extensão) da escola básica. Dito de outra forma, a partir dessa análise foi reafirma a nossa ideia inicial que existia a lacuna de um blog e de uma comunidade no Facebook dedicado à didática das ciências.

Dessa forma, a partir de março deste ano, começamos a reunir e publicar no sítio e na comunidade do Facebook Cientista Didático informações que circulam pela rede sobre a relação entre a didática e ciências. Entre os assuntos difundidos contemplase tanto o ponto de vista da didática sobre diferentes conceitos científicos, quando o olhar de alguns cientistas sobre a didática de sua disciplina. Algumas vezes são utilizadas fontes bibliográficas diversas, como livros impressos, porém a ênfase é a compilação de conteúdos digitais com a intenção de levar aos professores das disciplinas científicas algumas abordagens sobre os conceitos científicos com os quais trabalha e as diferentes formas de sua apresentação. As informações que serão reunidas se encontram em ferramentas da web como YouTube.com ou Flickr.com, por exemplo. 
Mas também envolvem a revisão de artigos que podem ser encontrados no Scielo.org, no Web of Knowledge ou no Scopus.com.

Procura-se produzir de três a quatro postagens por semana, que estão relacionadas aos seguintes assuntos: conceitos específicos (em que se procura apresentar a abordagem de algum conteúdo curricular através da utilização das mídias que podem ser encontradas na rede; resenha (em que se faz alguma indicação, comentário ou crítica de alguma ferramenta ou página encontrada na rede); biografia ou perfil (onde se apresenta algum cientista que tenha trabalhos relevantes para a didática de sua disciplina); metodologia (onde de apresentam de forma comentada as principais abordagens da didática, da psicologia ou da sociologia que são utilizadas no ensino de ciências e de tecnologia); entrevista (em que se divulga o pensamento de alguns dos principais educadores em ciências do Brasil acerca das características contemporâneas do ensino de sua disciplina, envolvendo, por exemplo, a utilização das tecnologias de informação e de comunicação no ensino de ciências).

Atualmente, devido às características dos autores, há maior ênfase em assuntos relacionados à química e à psicologia da educação. Porém, como se esses assuntos não fosse tarefa suficiente, pretendemos logo que possível ampliar os temas abordados. Pretendemos, a partir da regularidade de nossas postagens estabelecer uma comunidade virtual ativa no âmbito da didática das ciências que possibilite efetivas interações e trocas de conhecimentos que sirvam para a melhoria geral do ensino de ciências e de química nas escolas dos membros dessas comunidade virtual.

$\underline{\text { Agradecimento }}$

Ao $\mathrm{CNPq}$, pelo financiamento concedido à bolsa de apoio técnico à pesquisa que nos permitiu produzir e manter o blog e página no Facebook Cientista Didático (www.cientistadidatico.com.br).

$\underline{\text { Referências bibliográficas }}$

BARCELOS, G. T.; PASSERINO, L. M.; BEHAR, P. A. Proposta de Formação para Integração das Tecnologias de Informação e Comunicação às Práticas Docentes de Professores de Matemática. Em: Congresso Iberoamericano de Informática Educativa (IE 2010), 1-3 dez. Santiago, Chile, 2010.

BAR-ILAN, J. Information Hub Blogs. Journal of Information Science, 31 (4), 297 307, 2005.

BARRO, M. R.; FERREIRA, J. Q.; QUEIROZ, S. L. Blogs como ferramenta de apoio ao ensino presencial em uma disciplina de comunicação científica. Em: XIV Encontro Nacional de Ensino de Química. Curitiba: Sociedade Brasileira de Química, 2008a.

BARRO, M. R.; FERREIRA, J. Q.; QUEIROZ, S. L. Blogs: aplicação na educação em química. Química Nova na Escola, 30, 10-15, 2008 b.

BARRO, M. R. Blogs como ferramenta de apoio ao ensino presencial em uma disciplina de comunicação científica para graduandos em química. Dissertação (Mestrado em Ciências) - Instituto de Química de São Carlos, Universidade de São Paulo, São Carlos, 2009.

BASSANI, P.B.S.; HEIDRICH, R. O. Corpo e tecnologia: um estudo das redes sociais na Web. Revista Novas Tecnologias na Educação, 6, 12a, 2008.

BROWNSTEIN, E.; KLEIN, R. Blogs: applications in science education. Journal of College Science Teaching, (35), 6, 18-22, 2006.

CAPRA, F. Vivendo Redes. Em: DUARTE, F.; QUANDT, C.; SOUZA, Q. (org.) O tempo das redes (pp.17-29). São Paulo: Perspectiva, 2008. 
CARVALHO, A.A.; MOURA, A.; PEREIRA, L.C.S. Blogue: Uma ferramenta com potencialidades pedagógicas em diferentes níveis de ensino. Em: Actas do VII Colóquio sobre Questões Curriculares - III Colóquio Luso-Brasileiro sobre Questões Curriculares (pp. 635-652), Portugal: Braga, 9 a 11 Fev., 2006.

CASTELLS, M. A Sociedade em Rede - A era da informação: economia, sociedade e cultura. Editora São Paulo, Paz e Terra, 1999.

CASTELlS, M. A Era da Informação: o Poder da Identidade. São Paulo: Paz e Terra, 2002.

CASTELLS, M. A era da intercomunicação. Le Monde Diplomatique, agosto de 2006. COUTINHO, C.P.; BOTTENTUIT Jr, J.B. Collaborative learning using wiki: a pilot study with master students in educational technology. Em: Proceedings of World Conference on Educational Multimedia, Hypermedia e Telecommunications. Vancouver, Canadá, 2007.

DREVES, A.T. Blog e jornalismo on-line: Potencialidades profissionais na contemporaneidade tecnológica. Faculdade de Pato Branco - FADEP, 2004.

GUTIERREZ, S. Weblogs e educação: contribuição para a construção de uma teoria. On-line. Revista Novas Tecnologias na Educação, 3 (1), 2005.

HRASTINSKI, S.; AGHAEE, N.M. How are campus students using social media to support their studies? An explorative interview study. Education and Information Technologies, 17 (4), 451-464, 2011.

HRASTINSKI, S.; DENNEN, V. Social media in higher education: Introduction to the special issue. Internet and Higher Education, 15 (1), 1-2, 2012.

LEITE, B.S.; LEÃO, M.B.C. Elaboração de um portal e de um blogger como suporte didático para o ensino de química. Em: XIV Encontro Nacional de Ensino de Química. Curitiba: Sociedade Brasileira de Química, 2008.

MACHADO, J.R., TIJIBOY, A.V. Redes Sociais Virtuais: um espaço para efetivação da aprendizagem cooperativa. Revista Novas Tecnologias na Educação, 3 (2), 2005.

MORESCO, S.F.S. e BEHAR, P.A. Blogs para a aprendizagem de Física e Química. Revista Novas Tecnologias na Educação, 4, (1), 2006.

PRIMO, A. Interação mediada por computador: comunicação, cibercultura, cognição. Porto Alegre: Sulina, 2007.

REAL, L.M.C.; MILLAN, G.L. Alfabetização Tecnológica Através da Construção de Blog. Revista Novas Tecnologias na Educação, 9 (1), p. 1-18, 2011.

RECUERO, R.C. Warblogs: os Blogs, a Guerra do Iraque e o Jornalismo Online. 2003. Disponível em: <http://www.pontomidia.com.br/raquel/warblogs.pdf> Acesso em: 8 mai 2012

Web 2.0 Applications as alternative Environments for Informal Learning - a Critical Review. Em: OCED-KERIS expert meeting, 2007.

SELWYN, N. Schooling the Mobile Generation: The future for schools in the mobilenetworked society. British Journal of Sociology of Education, 24 (2), 131-144, 2003.

SILVA, J.A.B. Weblogs: Múltiplas utilizações e um conceito. Em: XXVI Congresso Brasileiro de Ciências da Comunicação - Belo Horizonte (MG) - 2 a 6 Set, 2003.

SILVA, J.W.M.S. Recuperação de informação através de recursos da web semântica: modelagem e implementação (Relatório Técnico). João Pessoa: CEFETPB-GEET-CST, 2007.

SIMÕES, L.; GOUVEIA, L. Geração Net, Web 2.0 e ensino superior, Em: FREITAS, E. e TUNA, S. (Orgs.) Novos Média, Novas Gerações, Novas Formas de Comunicar. Edição especial Cadernos de Estudos mediáticos, n. 6. (pp 21-32). Edições Universidade Fernando Pessoa, 2009. 
WAISELFISZ, J.J. (2007). Lápis, borracha e teclado: tecnologia da informação na educação - Brasil e América Latina. Brasília: RITLA, Instituto Sangari, MEC. 